\title{
Theorizing the Concept of Urban Public Transportation Institutional Framework in Malaysia
}

\author{
Noor Ashikin Abd Rahman ${ }^{1}$ and Yusfida Ayu Abdullah ${ }^{2}$ \\ ${ }^{1}$ Centre of Postgraduate Studies, Faculty of Architecture, Planning and Surveying, Universiti Teknologi MARA, 40450 Shah Alam, Malaysia. \\ ${ }^{2}$ Centre of Studies for Town and Regional Planning, Faculty of Architecture, Planning and Surveying, Universiti Teknologi MARA, 40450 \\ Shah Alam, Malaysia.
}

\begin{abstract}
The trends in transportation have been changing and will continue to change over the years. Urban dwellers in developing countries require and demand for mobility and accessibility at the same growth rate of these urban areas. Often, this demand is accommodated by the increased number of private vehicles. Development of a country is closely linked with the transportation system facilities thus will have a positive impact on the economic growth and social fabric of a country. The traffic issues are always associated with private vehicles especially in any developing cities such as the Federal Territory of Kuala Lumpur. A practical, efficient and effective transport system includes traffic management, public transport, road network and infrastructure. However, sadly, at present, the traffic problems in Malaysia are resulted from ineffective public transport system which is not methodically integrated from one place to another, therefore, forcing the people to use private vehicles for daily exercise. An integrated and comprehensive approach is required as it enhances the regulatory framework, planning structure and level of services delivered. For that reason, this paper reviews the magnitude of urban public transportation institutional framework in order to improve the people's mobility, also to respond to the major problem of urban public transportation in the major city of Malaysia. This study therefore applies a case study design and relies very much on qualitative data encompassing policies and guidelines. The findings were drawn from an early investigation of the Malaysian institutional public transport framework through literature review which looks closely into the management structure, as well as the implementation of public transportation system and its enforcement.
\end{abstract}

\section{Introduction}

Over the past few years, urban development receives pressure from the economic growth and increasing population. Public transport is one of the main problems of the people in the city because it has a direct impact on their daily lives. This is proven by the number of articles and news about public transportation published in various mass media The Malay Online [1], BERNAMA [2], Astro Awani [3], The Malaysian Insider [4], My NewsHub [5], Mstar [6]. The problems include the issue of complexity of land use and the lack of holistic approach in development and planning strategies. Also, the lack of a comprehensive transportation planning resulting a connectivity gap and making the Land Public Transport's (LPT) services to be inefficient and not userfriendly, therefore suggesting a more cohesive effort between the Federal, States and Local Authorities [7]. According to Azmi and Fanim [7], there is no clear role and responsibilities among the governments. The development had led to institutional conflicts in several aspects especially in enforcement, infrastructure provision and use, policy formulation and coordination. It was agreed by Oni, Okanlawon, and Asenime [8] that the problem complexity, planning, implementation and enforcement should be reviewed seriously because there appeared to various ministries and agencies at the federal and local level involved in different aspects of public transport in the Klang Valley. Furthermore, the four thrusts have not been accomplished which ensures the efficacy of transportation i.e., a collaborative planning and governance system, regulatory strengthening, as well as the service quality and excellence, and the infrastructure and capacity [7]. Another issue relates to the urban transport system and management. The increasing population of Greater Kuala Lumpur (GKL) and the Klang Valley $(\mathrm{KV})$ is expected to reach 10 million in 2020, adding more pressure on its road network which is already nearing full capacity [9]. While the roads in GKL and $\mathrm{KV}$ are generally still serviceable, they are sensitive to any disruption that may have an impact to the entire system, causing massive congestion [9], for example, due to an accident on the road. Prolonged traffic congestion has numerous effects both to the social and economic. Fuel is wasted by idling vehicles, while productivity is lost as workers are caught in traffic, air quality is degraded by needless emissions and drivers are frustrated by the long commute into and out of the city [9]. The challenge is to therefore, maintain a robust network of private transport for the people who

1ashiqin.rahman@gmail.com,2, yusfida@salam.uitm.edu.my 
can afford private vehicles but also to practice an efficient public transportation networks and institutional framework that people can choose. The importance of a pragmatic institutional framework because it ideally covers a range of an organisational structure, including its regulations, policies, services and management of the whole system. It is therefore a form of linkages that ensures an effective flow of information from one part of a system to another [10].

Urban transport management approach had previously focused on methods to solve the problem of traffic congestion by building more roads and encourages the use and purchase of private vehicles. One of the main causes of traffic congestions in Kuala Lumpur (KL) is the substantial number of private vehicles with only a single occupant. This happens because of the very poor public transport system [4]. The inconsiderate Malaysian drivers was also claimed to be another reason [11]. The problem of congestion is generally caused by the lack of emphasis on managing the vehicles' movement and the lack of integration of public transport services [12]. The government, with the cooperation of the public, can resolve these issues by improving the driving behaviour, frequencies and intensities of buses plying the roads of KL. Looking at the Government Transformation Programme's (GTP) strategy, the ratio of private and public transport is still below the target with $12 \%$ in 2014 and when the government is trying to increase it to $25 \%$, which is when the public transportation system will become the preferable mode of urban transport [9].

With regards to those continuing issues, this paper, therefore, seeks to examine the significance of urban public transportation institutional framework in order to improve the people's mobility, and to respond to the major problems of urban public transportation in KL. Given that intention, this paper will review the current literature on public transportation and analyse its institutional framework, and thereafter suggests a fitting approach.

\section{Urban Public Transportation}

\subsection{The Background of Urban Public Transportation in Malaysia}

Malaysia is experiencing rapid development in order to achieve the Vision 2020, and because of this, an efficient transportation system is needed to enhance the productivity and encourages economic activities, thereby increasing the national output and competitiveness [13]. Kuala Lumpur itself is a booming city facing immense challenges in trying to accommodate additional private cars every year and the increased of motor vehicles is faster than the population growth [9]. The city struggles with air pollution and traffic congestion thus reduces the Quality of Good Life [14]. It is just not enough to rely on factors of convenience to encourage the behaviour of using public transport. Individuals, however, still prefer to purchase private cars instead of using public transport [15]. Individuals were seen as reluctant of being in a crowded train with strangers [16]. It is for these reasons that the policy makers should learn to understand the unique needs of the general public especially in terms of their dependency on private vehicles before committing to new major projects related to transportation.

Public transportation is, therefore, a cornerstone of a nation's economy which provides a transit medium for daily mobility and the link between the people and their jobs, education and entertainment. Service coverage, travel time, reliability, park and ride facilities, comfort and safety are among the determining factors towards encouraging public transportation as a mode of choice [17]. However, integrating land use and public transportation requires an orderly co-ordination and consensus from all related agencies.

Needless to say, public transportation system is being taken seriously especially in KL. This includes the multiple vehicle services designed to transport customers on local and regional routes. Public transportation is therefore provided to the general public by means of cars, buses, vans and trains, either privately or publicly owned. It also includes shared passenger services like taxicab, carpooling or hired buses which are not hired together with strangers without private arrangement.

The key to an affordable and sustainable public transport system is to consider the actual demand, region's characteristic, government policies and financial condition and to put in place a transportation system that suits the local condition. A good system requires a combination of various elements.

\subsection{Integration of Urban Public Transportation System}

The term 'integration' in public transport is similar to the concept of intermodal which is generally used for the transport of goods. This concept is usually defined as a system that provides seamless public transport services for passengers and covers a wide range of concepts. Netherlands Transport Research and Training [18] quotes by European Cooperation Project [18] and Poorjafari [18] defines integration as:

"The organisation process through which elements of the passenger transport system (network and infrastructure, tariffs and ticketing, information and marketing, etc are across modes and operators, brought into closer and more efficient interaction, resulting in a overall positive enhancement to the overall state and quality of the services linked to the individual travel components"

This definition however goes further and includes a wider incorporation with other transport modes and nontransport services such as town planning, environment and social policies [18]. There are a variety of measures and practices to strengthen the integration within and amongst the public transport system such as physical and network, fare, information and institutional. A common institutional framework is the key instrument to land use planning, travel demand and integrated public transport services. This combination is important to improve the cooperation and coordination among authorities or 
government agencies, public transport sectors and between private and public operators. Integration can occur through four (4) manners such as incorporation between policy instruments involving different modes, integration between policy instruments involving infrastructure provision, management, information and pricing, integration between transport measures and land use planning policies etc. [18]. Integration is not a definite status and should be improved continuously within different public transport modes and also between public transport and other transport modes. Integration can be implemented and achieved at different levels. However, the higher level of integration is achieved by extending its border beyond the public transport systems by involving other modes of transport and other policies.

A decent public transport system is taking into account the 'network effect'. This is an inter-connecting train, tram and bus system, where timetables and exchanges correspond and interlock permitting 'anyplace to-anyplace' traverse a city. It also has a system of public transport lines where the structure is simple and the timetable is steady, making it easy for the people to learn and comprehend it. While public transport critics regularly assert that public transport just works in populaces with high thickness, the confirmation indicates something else [19].

\subsection{Institutional Framework for Transportation Planning and Management System}

Institutions are a set of norms, values and beliefs that have been formed to ensure that targets are achieved while framework is the linkage that supports two or more sub-systems ensuring the easy flow of information or data from one sub-system to another [10]. The major components of the institutional framework include the governance framework (three tiers government), the organisational framework (planning authorities) and legislative framework (planning laws) and administrative framework (structure). Institutional structure is an instrument used to achieve better governance because they have the potential to bring about changes in outcomes. Pinto [20] observed that the best institutional structures for urban governance which have values embedded in the basic purposes of society. The relationship between the institution's framework and its structure would ensure central control and domination in any level of governance. The transportation planning and management system is made of various public and private actors. The issues and problem faced by the planning and management system include a lack of coordination between the public and private sectors, insufficient capability to carry out planning at appropriate scales, enforcement problems [21].

At present, a range of public and private institutions have responsibilities for transportation in KL. There are a lot of agencies focusing on public transport in Malaysia such as the Prime Minister's Office, Economic Planning Unit (EPU), Ministry of Finance Malaysia, Ministry of Housing, Urban Wellbeing and Local Government, Ministry of Transport Malaysia, Ministry of Works
Malaysia, Ministry of Federal Territories, Ministry of Natural Resources and Environment, Ministry of Home Affairs and also Land Public Transport Commission (SPAD). These agencies are responsible and form part of the institutional framework for urban public transport in Malaysia whether directly or indirectly. Malaysia has a three tier types of government: the federal, state and local government [21]. In general, the Federal Government is responsible for determining national transportation plans, transport policy guidelines and overall administrative matters. Local governments on the other hand, plan, execute and administer road networks and urban transport improvements under their jurisdiction.

The local government's institutions deal with daily urban transport problems and responsible for the planning, construction and maintenance of transport facilities in their jurisdiction. The City Hall of Kuala Lumpur is governed by its own set of regulations and carries out its own planning, design, implementation and maintenance of road transport among other functions. The function of a local government is very limited as the federal government's institutions determine the general plans and major government financed infrastructural projects. The local government is therefore responsible only for the planning and development of smaller projects [21].

\section{Research Methodology}

This paper focuses more on reviewing the current literature. It examines the concept and practice of urban public transportation and analysed the public institutional framework. However, further to that, the research will engage a case study approach and therefore investigate the existing institutional framework for urban transportation, including its delivery and management of public transportation by the government and related agencies.

The selected study area to conduct this research is the Federal Territory of Kuala Lumpur (KL) based on its substantial role as the capital city and most popular city in Malaysia amid its continual challenges for public transportation (Figure 1). The city covers an area of 243 $\mathrm{km}^{2}$ and with an estimated population of 1.6 million. The local administration is carried out by the Kuala Lumpur City Hall or Dewan Bandaraya Kuala Lumpur (DBKL) under the Federal Territories Ministry of Malaysia. Kuala Lumpur City Hall is therefore responsible for KL's urban public transportation institutional framework, working together with the federal government. KL was also chosen for this research because of the immense challenges it faces in trying to accommodate additional private cars every year and the increased of motor vehicles which is faster than the population growth.

It was highlighted that KL needs a suitable and complete network system which provides road accessibility and high quality public transportation service in major routes that provides a seamless transportation system. In supporting the sustainable transport system, these criteria should be emphasised [22] 
such as to enhance the comfort and convenience; improves accessibility to land public transport through an integration of local land use policy and focusing on Transit Oriented Development (TOD); undertakes comprehensive and integrated planning (consider the planning, integration and coordination of all mode of transport); and strengthens institutions role and framework. Hence, the institutional framework structure which involves the administration at the federal, level and local level is crucial in such development.

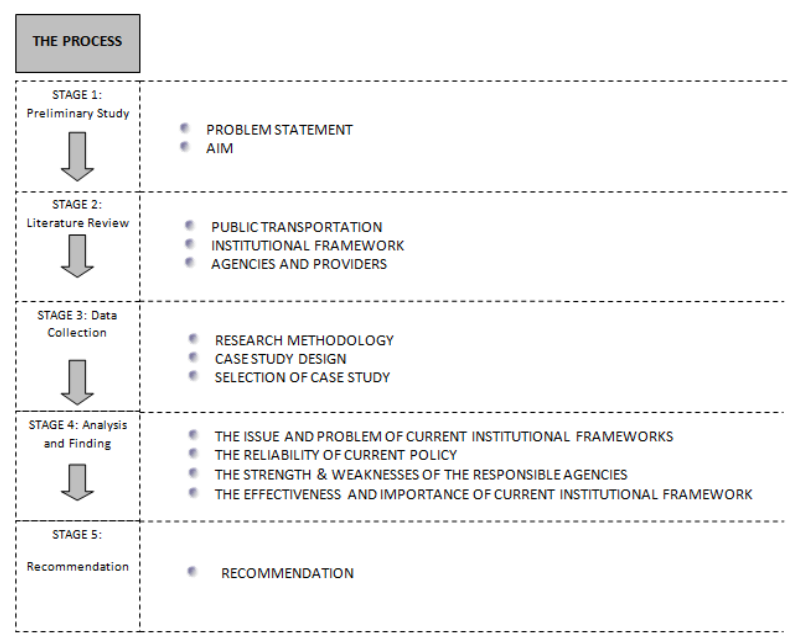

Figure 1. Approach to Case Study

The factors that influence the selected study area were also based on the urban public transport problem and issues. The lack of coordination and integration between internal and external institutional framework itself especially on administration of urban public transport, the management and operation of public transportation, the system and procedure for project implementation and also the sources of finance are the major contributing to the problem in this field [18].

\section{Analysis and Discussion}

Based on the study, it was apparent that urban public transportation in KL faces many challenges in relation to its institutional framework (Figure 2):

(a) There is no clear and coherent policy framework where public transport is clearly seen as a key to guarantee the nation's future success. During the Tenth Plan period, Land Public Transport Commission (SPAD) implemented four strategies which focused on strengthening the regulatory framework, increasing transport capacity, promoting seamless connectivity and establishing a robust monitoring and enforcement mechanism. However, The National Land Public Transport Master Plan only guides the formulation of regional master plans and preparation of policy guidelines. Therefore, there it lacks in integration between the urban transport policies and the public transport system itself due to the fact that there is no precise national policy formulated to overcome the land public transport issues.

(b) The lack of comprehensive planning is one of the key factors which create connectivity gaps thus rendering the public transport services inefficient and not user friendly. A cohesive and concerted effort between the Federal, States and Local Authority needs to be critically established with clearly defined roles and responsibilities to ensure a seamless system is put in place. The transformation of public transport responsibility led by SPAD in collaboration with various agencies. However, poor coordination among agencies during planning and implementation of the various transport initiatives has led to inefficient utilization of resources such as the construction of urban rail and highway in the same corridor. In addition, public transport improvements require a stronger integration in land use planning and the involvement of local authorities.

(c) SPAD has established a public transport committee at the state level to guide and consult with state and local authorities. However, the committee had not performed accordingly in the implementation of public transport improvement plan. There appeared to be the lack of coordination between public transport and urban planning. Moreover, the lack of emphasis in terms of transport planning and administration, management and operation of transit systems, institutions for project and program implementation and also shortage of finance are affecting the overall system [12].

(d) Lack of integration between urban public transport system (public transport unavailability) whereas the five broad categories are important such as physical, network, fare, information and institutional integration and also minimal public transport coverage in certain areas where this is the issues faced by the public [23].

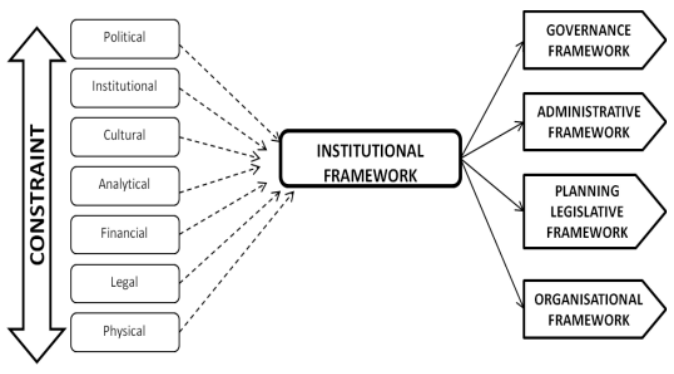

Figure 2. Findings of the Research

Many of the key challenges indentified for the development of land public transport services in Malaysia enfold around the need to strengthen the regulatory framework and improving the level of services for public transport by integrating all of them. The formulation of national policy should become the priority where government needs to recognise the importance of urban mobility issues. There are already many countries around the world where governments are taking concerted action 
on urban mobility including Sweden, Abu Dhabi and Singapore, whereby public transport is clearly seen as key tool to guarantee the nation's future success.

\section{Recommendations}

The following recommendations are proposed to improve the current institutional framework of urban public transportation in KL particularly, and in Malaysia generally.

(a) Creating A Clear and Coherent Policy Framework and Governance

Successful mobility in cities starts at the very top of the policy-making chain. Government should recognise the importance of urban mobility issues nationally and ensure they are high up on the policy agenda. It is essential to have a national legal and regulatory framework of public transport to become more viable and stable. Clear roles and responsibilities need to be defined for each stakeholder in the mobility supply chain in delivering real results on the ground. A proposed institutional framework for urban public transportation in KL is illustrated below (Figure 3).

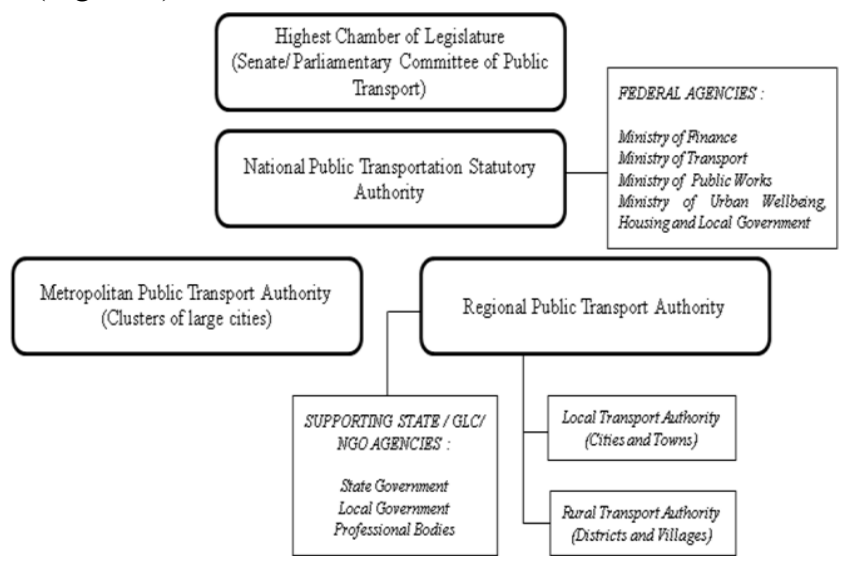

Figure 3. Proposed Institutional Framework for Urban Public Transportation in KL

Through SPAD, there should be a Public Transport Authority who is responsible in ensuring the standards in determining access to key performance benchmark for the entire country. Integrated public transport planning policy should be aligned with the Nation Physical Plan (NPP) and the Public Transport Authority is responsible in mobilizing the cooperation of ministries and agencies of government support related to public transport through a clearer scope of responsibility and performance appraisal. Furthermore, the Klang Valley desirable to have the Regional Public Transport Authority itself where it has jurisdiction to develop a support system for an effective public transport from residential areas to the central of Klang Valley, Kuala Lumpur.

(b) Integrating Public Transport and Urban Planning
The problems such as lack of institutional and regulatory framework, non-integration of transport to urban planning, mismanagement of traffic can be solved if better coordination between public transport and urban planning would bring many far-reaching benefits. It can help control urban sprawl, foster urban regeneration and promote sustainable transport mode a viable and attractive option. Coordination between these two policy areas can be improved by developing a shared vision across all policy sectors, fostering cooperation between public authorities and private property developers, prioritising public transport-oriented urban design.

\section{(c) Integrating Transport Modes}

Integrating transport modes in KL can encourage people to use the public transport. Nevertheless, this is not a straightforward task to achieve and so a coordinated approach is the only way to achieve an integrated and seamless public transport system. All the main players should need to pull in the same direction and different transport modes and different transport companies need to work together (Figure 4). This direction will inevitably requires the synchronisation of the federal agencies, along with other related agencies like SPAD and most importantly the KL City Hall.

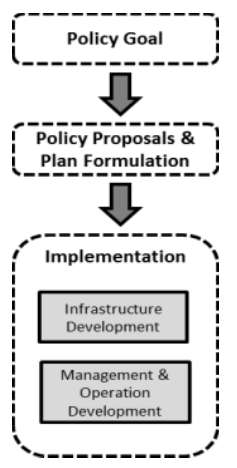

Figure 4. Proposed Urban Public Transportation Strategy

An urban transport strategy has been formulated with a long-term policy goal or vision. In addition to strategic policy proposals to achieve the long-term goal, a set of feasible projects and measures must be proposed for implementation accompanied by operation and management requirements.

\section{Conclusion}

A city like Kuala Lumpur would easily be communicated if the traffic flow runs smoothly and orderly and when there is integration between the public transport systems. Likewise, this can be achieved through good planning. Cities should be able to provide an efficient urban structure and equitable society which all members can easily gain access to all the amenities and enjoy the maximum benefits of city life. Furthermore, the implementation of effective public transport system is the key solution in improving people mobility and also to 
counter the major problem of urban public transportation. With the right regulatory and institutional framework in place, KL will have the power to define how they can encourage the people to use public transport. This paper has unveils the important issue of integration among agencies. As mentioned earlier about the methodology, further work will embark on the case study approach and will examine closely at the practice in Kuala Lumpur.

Putting in place successful public transport projects is a major aspiration that brings significant benefits. In order to achieve a maximum impact, the integration of the public transport policy and urban planning needs to be mainstreamed in policy decisions at local and national level. The higher level of integration is achieved by extending its border beyond the public transport systems by involving other modes of transport and other policies, like land use planning, social and environmental policies. The coherence between policy and public transport will indirectly integrate between public transport and urban planning and also public transport modes.

\section{Acknowledgments}

The authors would like to thank the Public Service Department of Malaysia for funding the research. And, to thank the Universiti Teknologi MARA (UiTM) and the Centre facilities and support.

\section{References}

1. The Malay Online. Improve The Quality of Public Transport Services. 2 October 2014 (2014).

2. BERNAMA. Public Transport Fare Increase Is Necessary. 17 April 2015 (2015).

3. Astro Awani. Reorganisation Of The Department: Solve Public Transport Problem. 27 July 2015 (2015).

4. The Malaysian Insider. Public Transport In $K L$ Needs To Be Improve Due To Increasing Users. 23 December 2014 (2014).

5. My News Hub. Improve Quality Of Services will Increase People Mobility. 11 October 2014 (2014).

6. Mstar. Logistic and Transport Sector Remains Priority. 21 May 2015 (2015).

7. Azmi Abdul Aziz \& Nor Fanim Mohd. Amin. Transforming The Land Public Transport System In Malaysia. Journeys (2012).

8. Oni,S.I,Okanlawon,K.R \& Asenime,C.O. Institutional Framework For The Transformation of Transport Administration in Metropolitan Lagos In An Agenda for a New Nigeria: The Imperative of Transformation, Anifowose, R.and Babawale,T.(eds.). Concept Publications Limited (2006).

9. Government Transformation Programme. Annual Report 2014, Government of Malaysia (2014).

10. Wapwera,S.D, Mallo D.M. and Jiriko G.J. Institutional Framework And Constraints In The Urban And Regional Planning System In Jos Metropolis, Nigeria. Journal Of Geography (2015).
11. The Star Online. System To Suit Public Needs. 13 February 2014 (2014).

12. Ministry of Transport. Strategy Paper - Providing Seamless Transportation. Government of Malaysia (2014).

13. Economic Planning Unit. Eleventh Malaysia Plan (RMK-11). Government of Malaysia (2015).

14. McKinsey \& Company How To Make A City Great. Europe (2013).

15. Public Transport User Assosiations. Public Transportation. Victoria,Australia (2010).

16. Department of Transport London. Travel Training : Good Practice Guidance. The National Archives, London (2011).

17. Land Transport Authority. Land Transport Authority Annual Report. Singapore (2014).

18. Poorjafari, V., \& Poorjafari, M.. Integration in Urban Public Transport Systems. Journal (2011).

19. Arief Irsyad. The Problem With Malaysia's Public Transport. Is Change On The Horizon?. Malaysian Digest.com. Retrieved on 7 February 2016. (2015)

20. Pinto MR. Metropolitan City Governance in India. New Delhi Sage (2000).

21.Zulina Zakaria. The Institutional Framework for Urban Transportation and Land Use Planning and Management in the Globalizing Kuala Lumpur Region. Research Paperwork (2003).

22. Global Development Research Center. Sustainability Dimensions of Transport Systems. Japan (2015).

23. Land Public Transport Commission. Greater KL/Klang Valley - Land Public Transport Master Plan. ALMEC Corporation (2012). 